\title{
Interval-Valued Intuitionistic Fuzzy Multicriteria Group Decision Making Approach for Hotel Selection
}

\author{
Santoso Wibowo, Senior Member, IACSIT
}

\begin{abstract}
Evaluating and selecting the most suitable hotel location for development is complex and challenging. To effectively deal with this problem, this paper presents an interval-valued intuitionistic fuzzy multicriteria group decision making approach for evaluating and selecting hotel locations. The subjectiveness and imprecision of the decision making process are adequately modeled by the use of interval-valued based intuitionistic fuzzy numbers. The concept of ideal solutions is adopted for determining the overall performance of each alternative hotel location across all the selection criteria on which the final decision is made. An example is presented for demonstrating the applicability of the proposed approach for solving real world hotel location selection problems.
\end{abstract}

Index Terms-Group decision making, hotel evaluation and selection, interval-valued based intuitionistic fuzzy numbers, subjectiveness and imprecision.

\section{INTRODUCTION}

The tourism industry is the fastest growing industry in the $21^{\text {st }}$ century [1]. Recent surveys have indicated that tourism is currently a major contributor in global economic development [2]. According to the Taiwanese Tourism Bureau, $46.09 \%$ of the expenditures from tourists are made within their hotels [2]. This statistic reflects the importance of the hotel sector in the tourism industry development and shows that the development of international tourist hotels will clearly benefit from this tourism industry. In fact, a forecast from the Pacific Asia Travel Association indicates that the tourism industry will be the fastest growing industry over the next decade [3]. As a result, it is crucial for hotel entrepreneurs to take advantage of this growing demand from tourists by expanding their market share through new hotels development.

In order for hotel entrepreneurs to gain a competitive advantage in the establishment of new hotels, it is critical that the most suitable hotel location is selected. This is because the selection of the most suitable hotel location has important strategic implications including an increase in market share and profitability [2], [3]. In fact, numerous researches have indicated that hotel location is the significant factor influencing operation performance in the future [1]. As a result, evaluating and selecting the most suitable hotel location from many available hotel locations becomes a critical decision to be made in the tourism industry.

Evaluating and selecting the most suitable hotel location

Manuscript received September 14, 2012; revised November 27, 2012.

Santoso Wibowo is with the School of ICT, Central Queensland University, Melbourne, VIC 3000 Australia (e-mail:s.wibowo1@cqu.edu.au). for development is complex and challenging. This is due to (a) the involvement of multiple decision makers, (b) the multi-dimensional nature of the decision process, and (c) the need for adequately modeling the subjectiveness and imprecision inherent in the decision making process. As a result, structured approaches are desirable for effectively dealing with the hotel location evaluation and selection problem.

This paper presents an interval-valued intuitionistic fuzzy multicriteria group decision making approach for evaluating and selecting hotel locations. The subjectiveness and imprecision of the decision making process are modeled by the use of interval-valued based intuitionistic fuzzy numbers. The concept of ideal solutions is adopted for determining the overall performance of each hotel location alternative across all the selection criteria on which the final decision is made. An example is presented for demonstrating the applicability of the proposed approach for solving the hotel location selection problem.

\section{A Hotel Selection Problem}

A hotel location problem has drawn increasing attention from academic and business communities in the past two decades [5]. This is because the selection of a hotel location has important strategic implications and it normally involves a long-term commitment of resources. On top of that, a good hotel location does not only increase market share and profitability, but also helps in satisfying the customer requirements and enhancing the convenience of the customer which will have a direct impact on the customer's loyalty [1], [6]-[8].

There are various factors that affect the selection of hotel locations in an organization. Much research has been done on identifying the critical factors for determining the suitability of hotel locations in an organization [1], [2], [5]-[10]. Pan [5], for example, states that a suitable hotel location should be convenient to traffic, public facilities such as commercial areas, conventional centres, and airports, and flexible space for future development. Tseng [6] believes that geographic factors, natural resources, and the size of the location are major criteria for the hotel selection. Furthermore, the quantity and quality of local human resources is also a focal point for organizations when making decisions on the establishment of hotels. Gray and Liguori [7] suggest several considerations for hotel location selection including local economic environment, regional or zone regulations, height limit of buildings, car park and public facilities, and traffic convenience and accessibility. Chiang et al. [8] believe that the three most important factors for hotel location selection 
are the size and nature of the city in which the hotel is located, the infrastructure within the region, and the perception of the region as an attractive business and tourist location. Meanwhile, Sun and $\mathrm{Lu}$ [9] state that labour quality, infrastructure and government policy are important factors for hotel location selection. Hsieh and Lin [2] explain that the overall facilities surrounding the region, traffic conditions, and future considerations for expandability are factors for consideration in the hotel location selection. Cheng et al. [10] state that the number of competitive store in the region, the degree of proximity to competitor locations and the future development potential are important factors for hotel location selection.

A comprehensive review of the related literature shows that the hotel location evaluation and selection problem can be formulated as a multicriteria analysis problem. Four most important criteria are identified for evaluating and selecting hotel locations including Geographical Location $\left(C_{l}\right)$, Traffic Condition $\left(C_{2}\right)$, Hotel Facilities $\left(C_{3}\right)$, and Operational Convenience $\left(C_{4}\right)$. Fig. 1 shows the hierarchical structure of the hotel location evaluation and selection problem.

Geographical Location $\left(C_{l}\right)$ refers to the strategic location of the hotel towards achieving its competitive advantage. It is often measured by the proximity of the location to public facilities, the distance to existing competitors, the public security around the location, the natural resources available, and the nearby rest facilities [2].

Traffic Condition $\left(C_{2}\right)$ focuses on the level of convenience of the situated hotel to various locations of interest. This is often measured by the distance to airport or freeway, the distance to downtown area, the distance to tourism scenic spots, the parking area, the convenience of freeway, the extensiveness of traffic routes, and the convenience to tourism scenic spots [1], [5].

Hotel Facilities $\left(C_{3}\right)$ concern with the ability of the hotel to provide both facilities and services for fulfilling the requirements of the customer's expectations. This includes the indoor leisure facilities, the diversity of restaurants in the hotel, the amalgamation with local culture, and the convenience of obtaining nearby land [3].

Operational Convenience $\left(C_{4}\right)$ reflects on the key resources necessary for supporting the business operations of the hotel. This is assessed from the sufficiency of human resources, the quality of manpower available, the land cost, and the regulation restrictions [2].

Based on the discussion above, it can be seen that the hotel location evaluation and selection problem is challenging due to (a) the involvement of multiple decision makers, (b) the multi-dimensional nature of the decision process, and (c) the need for adequately modeling the subjectiveness and imprecision inherent in the group decision making process.

To effectively evaluate and select the most suitable hotel location in a given situation, it is important for the decision makers to simultaneously consider the multiple selection criteria discussed as above. To facilitate the evaluation and selection of the most appropriate hotel location, an effective interval-valued intuitionistic fuzzy multicriteria group decision making approach is presented in the following section.

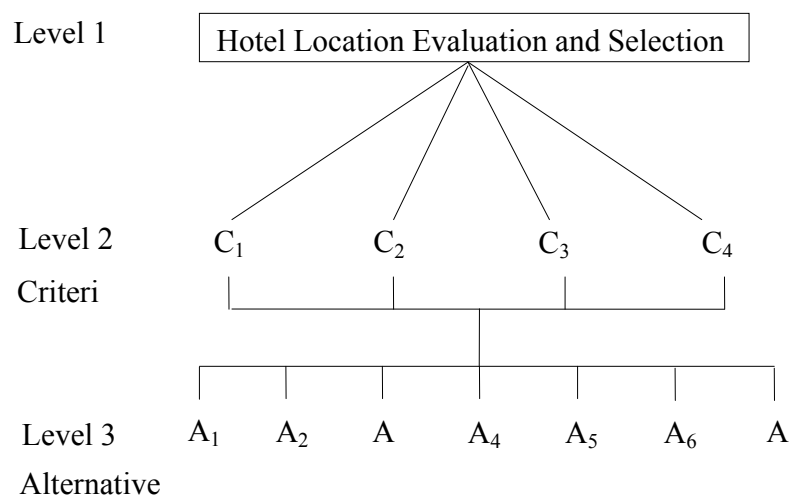

Legend

$\mathrm{C}_{1}$ : Geographical Location $\quad \mathrm{C}_{2}$ : Traffic Condition

$\mathrm{C}_{3}$ : Hotel Facilities

$\mathrm{C}_{4}$ : Operational Convenience

$A_{i}(i=1,2, \ldots, n)$ Hotel Location Alternatives

Fig. 1. The Hierarchical Structure of the Hotel Location Evaluation and Selection

\section{THE INTERVAL-VALUED INTUITIONISTIC FUZZY} MULTICRITERIA GROUP DECISION MAKING APPROACH

Multicriteria group decision making involves in evaluating a set of decision alternatives with respect to multiple, often conflicting criteria for selecting the most appropriate alternative in a given situation with multiple decision makers [11]. Formulated as a multicriteria group decision making problem, the evaluation and selection of hotel locations usually involves in (a) discovering all the alternatives, (b) identifying the selection criteria, (c) assessing the alternatives' performance ratings and the criteria weights by individual decision makers, (d) aggregating the alternative ratings and criteria weights for producing an overall performance index for each alternative across all the criteria, and (e) selecting the most suitable alternative in the given situation [12].

Subjectiveness and imprecision are always present in decision making due to incomplete information, abundant information, conflicting evidence, ambiguous information, and subjective information [11], [13]. To adequately model the subjectiveness and imprecision of the decision making process, interval-valued based intuitionistic fuzzy numbers [15] are used for representing the subjective assessment of the decision makers.

Interval-valued based intuitionistic fuzzy numbers [16] are the generalization of the intuitionistic fuzzy numbers. Their fundamental characteristic is that the values of the membership function and non-membership function are intervals rather than exact numbers. The introduction of intervals for describing the value of membership and non-membership helps to reduce the cognitive demand on the decision makers in representing their subjective assessments in the decision making process [16].

The evaluation and selection process starts with the determination of the performance of each alternative $A_{i}(i=1$, $2, \ldots, n)$ with respect to each criterion $C_{j}(j=1,2, \ldots, m)$ by 
individual decision makers $D_{k}(k=1,2, \ldots, s)$. Intuitionistic fuzzy number $y_{i j}^{k}=\left(\left[a_{i j}^{k}, b_{i j}^{k}\right],\left[c_{i j}^{k}, d_{i j}^{k}\right]\right)$ can be used for representing the performance rating of alternative, in which $\left[a_{i j}^{k}, b_{i j}^{k}\right]$ indicates the degree that alternative $A_{i}$ satisfies the criterion $C_{j}$ whereas $\left[c_{i j}^{k}, d_{i j}^{k}\right]$ shows the degree that alternative $A_{i}$ does not satisfy the criterion $C_{j}$. As a result, an interval-valued based decision matrix for the multicriteria group decision making problem for each decision maker can be obtained as

$$
y_{i j}^{k}=\left[\begin{array}{cccc}
y_{11}^{k} & y_{12}^{k} & \cdots & y_{1 m}^{k} \\
y_{21}^{k} & y_{22}^{k} & \cdots & y_{2 m}^{k} \\
\cdots & \cdots & \cdots & \cdots \\
y_{n 1}^{k} & y_{n 2}^{k} & \cdots & y_{n m}^{k}
\end{array}\right]
$$

The criteria weightings $\underline{C}_{j}$ for each decision maker $D_{k}$ can be represented as

$$
w_{j}^{k}=\left(w_{1}^{k}, w_{2}^{k}, \ldots, w_{m}^{k}\right)
$$

where $w_{j}^{k}=\left(\left[e_{i j}^{k}, f_{i j}^{k}\right],\left[g_{i j}^{k}, h_{i j}^{k}\right]\right)$ is the interval-valued based intuitionistic fuzzy number obtained from the decision makers for assessing the relative importance of the selection criterion. $\left[e_{i j}^{k}, f_{i j}^{k}\right]$ indicates the degree where the decision maker considers the selection criterion $\underline{C}_{j}$ to be important whereas $\left[g_{i j}^{k}, h_{i j}^{k}\right]$ indicates the degree where the decision maker considers the criterion $C_{j}$ to be unimportant.

By averaging the fuzzy assessments made by individual decision makers as given in (1) and (2), the overall interval-valued based intuitionistic fuzzy decision matrix and the overall interval-valued based intuitionistic fuzzy weight vector can be obtained respectively as

$$
\begin{aligned}
X & =\left[\begin{array}{cccc}
x_{11} & x_{12} & \ldots & x_{1 m} \\
x_{21} & x_{22} & \ldots & x_{2 m} \\
\ldots & \ldots & \ldots & \ldots \\
x_{n 1} & x_{n 2} & \ldots & x_{n m}
\end{array}\right] \\
w_{j} & =\left(w_{1}, w_{2}, \ldots, w_{m}\right)
\end{aligned}
$$

The weighted interval-valued based intuitionistic fuzzy performance matrix that represents the overall performance of each alternative on each criterion can be determined by multiplying the interval-valued based intuitionistic fuzzy decision matrix in (3) and the interval-valued based intuitionistic fuzzy criteria weightings in (4) using interval arithmetic [13]. The overall weighted interval-valued based intuitionistic fuzzy performance matrix for the problem can be obtained as

$$
R=\left[\begin{array}{cccc}
r_{11} & r_{12} & \ldots & r_{1 m} \\
r_{21} & r_{22} & \ldots & r_{2 m} \\
\ldots & \ldots & \ldots & \ldots \\
r_{n 1} & r_{n 2} & \ldots & r_{n m}
\end{array}\right]
$$

where

$$
r_{i j}=\left[\begin{array}{l}
\frac{\sum_{j=1}^{m}\left[a_{i j}, b_{i j}\right]\left[e_{i j}, f_{i j}\right]}{\sum_{j=1}^{m}\left[e_{i j}, f_{i j}\right]}, \\
\frac{\sum_{j=1}^{m}\left[1-c_{i j}, 1-d_{i j}\right]\left[1-g_{i j}, 1-h_{i j}\right]}{\sum_{j=1}^{m}\left[1-g_{i j}, 1-h_{i j}\right]}
\end{array}\right]
$$

The concept of the ideal solution is first introduced as the best decision outcome in a given decision situation [17]. Such a concept is then extended to include the negative ideal solution in order to avoid the worst decision outcome in the decision making process [18]. This concept has since been widely used for solving practical decision problems [19] due to (a) its simplicity and comprehensibility in concept, (b) its computation efficiency, and (c) its ability to measure the relative performance of the decision alternatives in a simple mathematical form [13], [20].

To rank all the alternatives based on the weighted interval-valued based fuzzy performance matrix in (5), the concept of the positive and negative ideal solutions is used. The positive (or negative) ideal solution consists of the best (or worst) criteria values attainable from all the alternatives [18]. The most preferred alternative should not only have the shortest distance from the positive ideal solution, but also have the longest distance from the negative ideal solution. The fuzzy positive ideal solution $\alpha^{+}$and the fuzzy negative ideal solution $\alpha^{-}$can be determined respectively as

$$
\begin{aligned}
\alpha^{+}= & \left(\alpha_{1}^{+}, \alpha_{2}^{+}, \ldots, \alpha_{m}^{+}\right) \\
= & \left\{\left(\left[\left(\max _{i} a_{i j}, \max _{i} b_{i j}\right)\left|j \in J_{1},\left(\min _{i} a_{i j}, \min _{i} b_{i j}\right)\right| j \in J_{2}\right)\right],\right. \\
& \left.\left.\left.\quad\left[\left(\min _{i} c_{i j}, \min _{i} d_{i j}\right)\left|j \in J_{1},\left(\max _{i} c_{i j}, \max _{i} d_{i j}\right)\right| j \in J_{2}\right]\right)\right)\right\}
\end{aligned}
$$$$
\text { where } \alpha_{j}^{+}=\left[a_{j}^{+}, b_{j}^{+}\right],\left[c_{j}^{+}, d_{j}^{+}\right] \text {and }(j=1,2, \ldots, m) \text {. }
$$$$
\alpha^{-}=\left(\alpha_{1}^{-}, \alpha_{2}^{-}, \ldots, \alpha_{m}^{-}\right)
$$$$
=\left\{\left(\left[\min _{i} a_{i j}, \min _{i} b_{i j}\right)\left|j \in J_{1},\left(\max _{i} a_{i j}, \max _{i} b_{i j}\right)\right| j \in J_{2}\right)\right],
$$$$
\left.\left.\left.\left[\left(\max _{i} c_{i j}, \max _{i} d_{i j}\right)\left|j \in J_{1},\left(\min _{i} c_{i j}, \min _{i} d_{i j}\right)\right| j \in J_{2}\right]\right)\right\rangle\right\}
$$

where $\alpha_{j}^{-}=\left[a_{j}^{-}, b_{j}^{-}\right],\left[c_{j}^{-}, d_{j}^{-}\right]$.

Based on (7) - (8), the Hamming distance between alternative $A_{i}$ and the positive ideal solution and the negative solution can be calculated respectively as follows

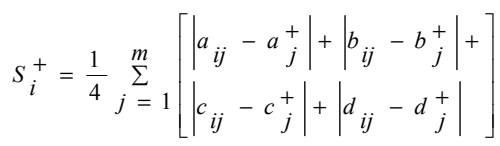

$$
\begin{aligned}
& S_{i}^{-}=\frac{1}{4} \sum_{j=1}^{m}\left[\begin{array}{l}
\left|a_{i j}-a_{j}^{-}\right|+\left|b_{i j}-b_{j}^{-}\right|+ \\
\left|c_{i j}-c_{j}^{-}\right|+\left|d_{i j}-d_{j}^{-}\right|
\end{array}\right]
\end{aligned}
$$

As a result, an overall performance index for each 
alternative $A_{i}$ across all the criteria can be determined by

$$
P_{i}=\frac{S_{i}^{-}}{S_{i}^{-}+S_{i}^{+}}
$$

The larger the performance index $P_{i}$, the more preferred the alternative $A_{i}$.

The interval-valued intuitionistic fuzzy multicriteria group decision making approach presented above is summarized as

Step 1. Obtain the decision matrix for each decision maker as expressed in (1).

Step 2. Determine the criteria weighting of each decision maker as expressed in (2).

Step 3. Obtain the overall interval-valued based intuitionistic fuzzy decision matrix and the overall interval-valued based intuitionistic fuzzy weight vector by (3) and (4) respectively.

Step 4. Obtain the weighted interval-valued based intuitionistic fuzzy performance matrix by multiplying the interval-valued based intuitionistic fuzzy decision matrix by the interval-valued based intuitionistic fuzzy criteria weightings as expressed in (5).

Step 5. Determine the fuzzy positive ideal solution and the fuzzy negative ideal solution using (7) and (8) respectively.

Step 6. Calculate the Hamming distance between alternative $A_{i}$ and the positive ideal solution and the negative solution by (9) and (10) respectively.
Step 7. Compute the overall performance index for each alternative by (11).

Step 8. Rank the alternatives in descending order of their index values.

\section{AN EXAMPLE}

To demonstrate the applicability of the interval-valued intuitionistic fuzzy multicriteria group decision making approach, an example of evaluating and selecting the most suitable hotel location from seven available hotel locations with respect to multiple decision makers and multiple evaluation and selection criteria is presented.

To start with the hotel locations evaluation and selection process, the relative performance of all available hotel locations in regard to decision makers $D_{1}, D_{2}$, and $D_{3}$ can be determined by making their subjective assessments using the interval-valued based intuitionistic based fuzzy numbers as shown in Table I.

Similarly, the criteria weights for selecting the hotel location alternatives can be obtained directly from the decision makers $D_{1}, D_{2}$, and $D_{3}$ as shown in Table II. Based on (3) - (5), the overall weighted interval-valued based intuitionistic fuzzy performance matrix for the hotel location evaluation and selection problem can be obtained. Table III shows the results.

TABLE I: PERFormanCe AsSESSMENTS OF Hotel LoCATION ALternatives

\begin{tabular}{|c|c|c|c|c|c|}
\hline & & $C_{1}$ & $C_{2}$ & $C_{3}$ & $C_{4}$ \\
\hline \multirow{3}{*}{$A_{1}$} & $\overline{D_{1}}$ & $([0.6,0.7],[0.2,0.3])$ & $([0.7,0.8],[0.1,0.2])$ & $([0.5,0.8],[0.1,0.2])$ & $([0.5,0.6],[0.1,0.3])$ \\
\hline & $\mathrm{D}_{2}$ & $([0.5,0.8],[0.1,0.2])$ & $([0.5,0.7],[0.2,0.3])$ & $([0.4,0.7],[0.1,0.2])$ & $([0.4,0.5],[0.3,0.4])$ \\
\hline & $D_{3}$ & $([0.5,0.6],[0.3,0.4])$ & $([0.7,0.8],[0.1,0.2])$ & $([0.7,0.8],[0.1,0.2])$ & $([0.5,0.6],[0.1,0.3])$ \\
\hline \multirow{3}{*}{$A_{2}$} & $D_{1}$ & $([0.3,0.6],[0.2,0.4])$ & $([0.5,0.6],[0.1,0.3])$ & $([0.1,0.3],[0.5,0.6])$ & $([0.5,0.8],[0.1,0.2])$ \\
\hline & $\mathrm{D}_{2}$ & $([0.5,0.7],[0.2,0.3])$ & $([0.5,0.8],[0.1,0.2])$ & $([0.6,0.8],[0.1,0.2])$ & $([0.5,0.7],[0.2,0.3])$ \\
\hline & $D_{3}$ & $([0.5,0.6],[0.1,0.3])$ & $([0.7,0.8],[0.1,0.2])$ & $([0.5,0.6],[0.3,0.4])$ & $([0.5,0.6],[0.1,0.3])$ \\
\hline \multirow{3}{*}{$A_{3}$} & $D_{1}$ & $([0.4,0.5],[0.3,0.4])$ & $([0.1,0.3],[0.5,0.6])$ & $([0.3,0.6],[0.2,0.4])$ & $([0.7,0.8],[0.1,0.2])$ \\
\hline & $D_{2}$ & $([0.3,0.7],[0.1,0.3])$ & $([0.7,0.8],[0.1,0.2])$ & $([0.5,0.8],[0.1,0.2])$ & $([0.6,0.8],[0.1,0.2])$ \\
\hline & $D_{3}$ & $([0.5,0.6],[0.1,0.3])$ & $([0.1,0.3],[0.5,0.6])$ & $([0.7,0.8],[0.1,0.2])$ & $([0.5,0.6],[0.3,0.4])$ \\
\hline \multirow{4}{*}{$A_{4}$} & $D_{1}$ & $([0.4,0.5],[0.3,0.4])$ & $([0.7,0.8],[0.1,0.2])$ & $([0.3,0.6],[0.2,0.4])$ & $([0.7,0.8],[0.1,0.2])$ \\
\hline & $\mathrm{D}_{2}$ & $([0.3,0.7],[0.1,0.3])$ & $([0.7,0.8],[0.1,0.2])$ & $([0.5,0.8],[0.1,0.2])$ & $([0.6,0.8],[0.1,0.2])$ \\
\hline & $D_{3}$ & $([0.3,0.7],[0.1,0.3])$ & $([0.1,0.3],[0.5,0.6])$ & $([0.7,0.8],[0.1,0.2])$ & $([0.5,0.6],[0.3,0.4])$ \\
\hline & $D_{1}$ & $([0.7,0.8],[0.1,0.2])$ & $([0.5,0.6],[0.3,0.4])$ & $([0.4,0.7],[0.1,0.2])$ & $([0.4,0.5],[0.3,0.4])$ \\
\hline \multirow[t]{2}{*}{$A_{5}$} & $D_{2}$ & $([0.3,0.7],[0.1,0.3])$ & $([0.3,0.7],[0.1,0.3])$ & $([0.5,0.8],[0.1,0.2])$ & $([0.4,0.5],[0.3,0.4])$ \\
\hline & $D_{3}$ & $([0.3,0.7],[0.1,0.3])$ & $([0.1,0.3],[0.5,0.6])$ & $([0.3,0.7],[0.1,0.3])$ & $([0.3,0.6],[0.3,0.4])$ \\
\hline \multirow{3}{*}{$A_{6}$} & $D_{1}$ & $([0.3,0.6],[0.3,0.4])$ & $([0.5,0.6],[0.1,0.3])$ & $([0.5,0.6],[0.1,0.3])$ & $([0.1,0.3],[0.5,0.6])$ \\
\hline & $D_{2}$ & $([0.5,0.6],[0.1,0.3])$ & $([0.3,0.6],[0.3,0.4])$ & $([0.3,0.7],[0.1,0.3])$ & $([0.5,0.6],[0.1,0.3])$ \\
\hline & $D_{3}$ & $([0.1,0.3],[0.5,0.6])$ & $([0.5,0.6],[0.1,0.3])$ & $([0.1,0.3],[0.5,0.6])$ & $([0.3,0.6],[0.3,0.4])$ \\
\hline \multirow{3}{*}{$A_{7}$} & $D_{l}$ & $([0.3,0.7],[0.1,0.3])$ & $([0.1,0.3],[0.5,0.6])$ & $([0.3,0.6],[0.3,0.4])$ & $([0.4,0.5],[0.3,0.4])$ \\
\hline & $\mathrm{D}_{2}$ & $([0.1,0.3],[0.5,0.6])$ & $([0.3,0.7],[0.1,0.3])$ & $([0.3,0.6],[0.3,0.4])$ & $([0.5,0.6],[0.1,0.3])$ \\
\hline & $D_{3}$ & $([0.3,0.6],[0.3,0.4])$ & $([0.5,0.6],[0.1,0.3])$ & $([0.5,0.6],[0.1,0.3])$ & $([0.3,0.6],[0.3,0.4])$ \\
\hline
\end{tabular}

TABLE II: CRITERIA WEIGHTS OF HOTEL LOCATION ALTERNATIVES

\begin{tabular}{|c|c|c|c|c|c|}
\hline & & $C_{1}$ & $C_{2}$ & $C_{3}$ & $C_{4}$ \\
\hline \multirow{3}{*}{ Criteria Weights } & $D_{1}$ & $([0.4,0.5],[0.3,0.4])$ & $([0.7,0.8],[0.1,0.2])$ & $([0.3,0.6],[0.2,0.4]$ & $([0.7,0.8],[0.1,0.2])$ \\
\hline & $D_{2}$ & $([0.5,0.8],[0.1,0.2])$ & $([0.6,0.8],[0.1,0.2])$ & $([0.6,0.7],[0.2,0.3])$ & $([0.3,0.6],[0.3,0.4])$ \\
\hline & $D_{3}$ & $([0.7,0.8],[0.1,0.2])$ & $([0.5,0.6],[0.3,0.4])$ & $([0.5,0.8],[0.1,0.2])$ & $([0.5,0.7],[0.2,0.3])$ \\
\hline
\end{tabular}


TABLE III: THE OVERALL WEIGHTED INTERVAL-VALUED BASED INTUITIONISTIC FUZZY PERFORMANCE MATRIX

\begin{tabular}{|c|c|c|c|c|}
\hline & $C_{1}$ & $C_{2}$ & $C_{3}$ & $C_{4}$ \\
\hline$A_{1}$ & $([0.68,0.89],[0.71,0.82])$ & $([0.48,0.67],[0.29,0.36])$ & $([0.79,0.87],[0.53,0.67])$ & $([0.61,0.87],[0.47,0.59])$ \\
\hline$A_{2}$ & $([0.51,0.87],[0.62,0.77])$ & $([0.57,0.72],[0.42,0.53])$ & $([0.46,0.67],[0.51,0.68])$ & $([0.45,0.57],[0.67,0.72])$ \\
\hline$A_{3}$ & $([0.51,0.66],[0.58,0.69])$ & $([0.47,0.68],[0.59,0.64])$ & $([0.45,0.57],[0.67,0.72])$ & $([0.51,0.66],[0.58,0.69])$ \\
\hline$A_{4}$ & $([0.45,0.62],[0.42,0.43])$ & $([0.43,0.72],[0.36,0.58])$ & $([0.68,0.83],[0.59,0.62])$ & $([0.61,0.87],[0.47,0.59])$ \\
\hline$A_{5}$ & $([0.48,0.67],[0.29,0.36])$ & $([0.36,0.47],[0.41,0.58])$ & $([0.46,0.67],[0.51,0.68])$ & $([0.42,0.54],[0.25,0.36])$ \\
\hline$A_{6}$ & $([0.36,0.47],[0.41,0.58])$ & $([0.43,0.72],[0.36,0.58])$ & $([0.43,0.72],[0.36,0.58])$ & $([0.51,0.66],[0.58,0.69])$ \\
\hline
\end{tabular}

By using (6) - (11), the overall performance index for each hotel location alternative across all the criteria can be calculated in a computational efficient manner. Table IV shows that alternative $A_{l}$ is the obvious choice for selection.

TABLE IV: THE PERFORMANCE INDEX OF HOTEL LOCATION ALTERNATIVES AND THEIR RANKINGS

\begin{tabular}{ccc}
\hline \hline Alternatives & Index & Ranking \\
\hline$A_{1}$ & 0.78 & 1 \\
$A_{2}$ & 0.69 & 4 \\
$A_{3}$ & 0.56 & 2 \\
$A_{4}$ & 0.62 & 3 \\
$A_{5}$ & 0.51 & 5 \\
$A_{6}$ & 0.41 & 7 \\
$A_{7}$ & 0.47 & 6 \\
\hline \hline
\end{tabular}

It is evident that the proposed approach is capable of effectively dealing with the involvement of multiple decision makers, the multi-dimensional nature of the decision process, and the presence of subjectiveness and imprecision in the multicriteria group decision making problem. With its simplicity in concept and efficiency in computation, the proposed interval-valued intuitionistic fuzzy multicriteria group decision making approach is capable of effectively solving the general multicriteria group decision making problem.

\section{V.CONCLUSION}

The hotel location evaluation and selection process is complex and challenging due to the involvement of multiple decision makers, the multi-dimensional nature of the decision process and the subjectiveness and imprecision inherent in the human decision making process. To effectively solve this problem, this paper has presented an interval-valued intuitionistic fuzzy multicriteria group decision making approach for dealing with the hotel locations evaluation and selection problem. A hotel location selection problem is presented that shows the proposed interval-valued intuitionistic fuzzy multicriteria group decision making approach is effective for solving the general hotel location selection problem.

\section{REFERENCES}

[1] W. T. Hung, J. K. Shang, and F. C. Wang, "Pricing determinants in the hotel industry: Quantile regression analysis," Int. J. Hosp. Manage, vol. 29, pp. 378-384, September 2010.

[2] L. F. Hsieh and L. H. Lin, "A performance evaluation model for international tourist hotels in Taiwan-An application of the relational network DEA," Int. J. Hosp. Manage., vol. 29, pp. 14-24, March 2010.
[3] T. Y. Chou, C. L. Hsu, and M. C. Chen, "A fuzzy multi-criteria decision model for international tourist hotels location selection," Int. J. Hosp. Manage, vol. 27, pp. 293-301, June 2008.

[4] C. Johnson and M. Vanetti, "Locational strategies of international hotel chains," Ann. Tour. Res., vol. 32, pp. 1077-1099, October 2005.

[5] C. M. Pan, "Market structure and profitability in the international tourist hotel industry," Tour. Manage., vol. 26, pp. 845-850, December 2005.

[6] K. J. Tseng, "A Performance Study on Independent-owned International Tourist Hotels in Taiwan," J. Int. Manage. Stud., vol. 3, pp. 79-88, February 2008.

[7] W. S. Gray, and S. C. Liguori, S. C., Hotel and Motel Management and Operations, third ed., New Jersey: Prentice-Hall, 1998.

[8] E. R. Chiang, M. H. Tsia, and L. S. M. Wang, "A DEA Evaluation of Taipei Hotel," Annu. Tour. Res., vol. 31, pp.712-715, July 2004.

[9] S. Sun, and W. M. Lu, "Evaluation the Performance of the Taiwanese Hotel Industry Using a Weight Slacks-Based Measure," Asia-Pacific J. Oper. Res., vol. 22, pp. 487-512, December 2005.

[10] H. Cheng, Y. C. Lu, and J. T. Chung, "Improved slack-based context-dependent DEA - A study of international tourist hotels in Taiwan,” Exp. Syst. Appl., vol. 37, pp. 6452-6458, September 2010.

[11] S. Wibowo, and H. Deng, "A Fuzzy Rule-Based Approach for Screening International Distribution Centres," Comput. Math. Appl., vol. 64, pp. 1084-1092, September 2012.

[12] S. Wibowo and H. Deng, "Intelligent Decision Support for Effectively Evaluating and Selecting Ships under Uncertainty in Marine Transportation," Exp. Syst. Appl., vol. 39, pp. 6911-6920, January 2012.

[13] C. H. Yeh, H. Deng, S. Wibowo, and Y. Xu, "Multicriteria group decision for information systems project selection under uncertainty," Int. J. Fuzzy Syst., vol. 12, pp. 170-179, June 2010.

[14] S. Wibowo, and H. Deng, "A Consensus Support System for Supplier Selection in Group Decision Making," J. Manage. Sci. Stat. Decis., vol. 6, pp. 52-59, December 2009.

[15] K. Atanassov and G. Gargov, "Interval-valued intuitionistic fuzzy sets," Fuzzy Sets Syst., vol. 31, pp. 343-349, July 1989.

[16] S. M. Chen, L. W. Lee, H. C. Liu, and S. W. Yang, "Multiattribute decision making based on interval-valued intuitionistic fuzzy values," Exp. Syst. Appl., vol. 39, pp. 10343-10351, September 2012.

[17] M. Zeleny, Multiple Criteria Decision Making, New York: McGraw-Hill, 1982.

[18] C. L. Hwang, and K. S. Yoon, Multiple Attribute Decision Making: Methods and Applications, Berlin: Springer, 1981.

[19] C. H. Yeh, H. Deng, and Y. H. Chang, "Fuzzy Multicriteria Analysis for Performance Evaluation of Bus Companies," Eur. J. Oper. Res., vol. 126, pp. 1-15, November 2000.

[20] H. Deng and S. Wibowo, "Intelligent decision support for evaluating and selecting information systems projects," Eng. Lett., vol. 16, pp. 412-418, August 2008.

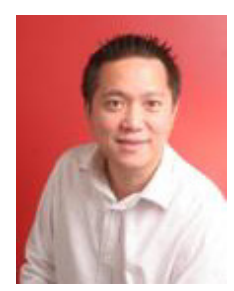

Santoso Wibowo received his $\mathrm{Ph} . \mathrm{D}$. degree in Business Information Systems from RMIT University, Melbourne, Australia. He is a senior lecturer at the School of ICT, Central Queensland University, Australia. His research interests include intelligent information systems, multicriteria decision analysis, knowledge management, and their applications for management decision making. 